\title{
As Contribuições do Pibid para a Formação Inicial e a Construção dos Saberes Docentes
}

\author{
Pibid's Contributions to Initial Training and the Building of Teaching Knowledge
}

\author{
Cristiane Katsue Miyazaki Nishiyama; Helenara Regina Sampaio Figueiredo*a
}

${ }^{a} U n o p a r$, Programa de Pós-Graduação Stricto Sensu em Metodologias para o Ensino de Linguagens e suas Tecnologias. PR, Brasil.

*E-mail: helenara@kroton.com.br

\begin{abstract}
Resumo
Este artigo tem por objetivo investigar as relações entre teoria e prática para a construção dos saberes docentes e as contribuições evidenciadas para os licenciandos de Pedagogia, participantes do Programa PIBID (Programa Institucional de Bolsas de Iniciação à Docência), em que se busca refletir as discussões sobre o PIBID e suas contribuições para o processo de formação inicial docente. Como referencial teórico são consideradas as três categorias dos saberes: Conhecimento, Pedagógico e da Experiência. Para alcançar o objetivo foi aplicado um questionário com questões semiestruturadas para trinta participantes do Programa Pibid da Universidade Pitágoras Unopar - Londrina. Apresentam-se os resultados da categoria "Saberes do Conhecimento" e da subcategoria "Ser Pedagogo". Os resultados evidenciam que os pibidianos mobilizam e desenvolvem saberes relacionados à profissão docente ao participar do PIBID. A vivência no PIBID oportunizou a reflexão sobre as competências profissionais e pessoais sobre ser um Pedagogo comprometido com a busca de ações efetivas para a conquista de uma educação de qualidade.
\end{abstract}

Palavras-chave: Competências Profissionais. Teoria. Prática. Licenciatura.

\begin{abstract}
This article aims to investigate the relationship between theory and practice for the building of teaching knowledge and the evidenced contributions for the Pedagogy Licensiature students participants in PIBID Program (Institutional Program for Teaching Initiation Scholarships), in which it is sougth to reflect the discussions about PIBID and its contributions to the initial teacher training process. As a theoretical framework, three knowledge categories are considered: Knowledge, Pedagogical and Experience. To achieve the objective, a questionnaire with semi-structured questions was applied to thirty participants in Pibid Program of Pitágoras Unopar University - Londrina. The results are presented of "Acquaintance of Knowledge" category and of the "Being a Pedagogue" subcategory. The results reveal that the PIBID students mobilize and develop knowledge related to the teaching profession by participating in PIBID. The experience at PIBID provided an opportunity for reflection on professional and personal skills about being a Pedagogue committed to the search for effective actions to achieve quality education.
\end{abstract}

Keywords: Professional skills. Theory. Practice. Licensiature Degree.

\section{Introdução}

Ao pensar na formação docente como processo de construção de saberes da profissão docente, permeada de estratégias de formação que possibilitem aos futuros professores a vivência, no ambiente escolar, e o desenvolvimento de saberes necessários para a atuação profissional, surge a necessidade de intensificar a relação entre Universidade e escola, sob a perspectiva de uma formação inovadora na Educação.

No que tange às oportunidades de criação e de participação em experiências metodológicas, tecnológicas e práticas docentes de caráter inovador e interdisciplinar, com vistas à valorização do magistério e da elevação da qualidade do ensino, o Programa Institucional de Bolsas de Iniciação à Docência (doravante PIBID) foi criado, em 2007, e suas contribuições para a formação inicial docente são evidenciadas por pesquisadores de todo o Brasil.
O PIBID da Universidade Pitágoras Unopar iniciou, pela primeira vez, suas atividades em setembro de 2018, com término em janeiro de 2020 e, ao longo dos meses, participaram do projeto institucional 72 discentes dos cursos de Pedagogia e Educação Física, os quais participaram do cotidiano escolar, das formações com os coordenadores de área e supervisores que interagiram com a comunidade escolar.

Diante desse cenário, foram investigadas algumas contribuições do PIBID para a formação inicial de pedagogos e as relações entre teoria e prática para a construção dos saberes docentes, evidenciadas pelos licenciandos de Pedagogia, apresentando-se os resultados da categoria "Saberes do Conhecimento" e da subcategoria "Ser Pedagogo".

\section{Material e Métodos}

Apresenta-se o referencial teórico que discute os saberes docentes e a formação inicial, os documentos de ensino que 
regem os cursos de Pedagogia da Educação Brasileira e o histórico do PIBID da Universidade Pitágoras UNOPAR, local no qual ocorreu a coleta de dados e os resultados das análises parciais.

\subsection{Saberes docentes e formação inicial}

A formação docente assume a centralidade nas discussões sobre qualificação profissional, no momento em que a escola vivencia uma crise de identidade diante do crescente desprestígio social e dos questionamentos sobre a competência profissional dos professores.

Tardif (2000) afirma que a crise do profissionalismo, que envolve a docência, é um movimento internacional, face ao desprestígio profissional e a desconfiança da sociedade no papel social que o docente desempenha. Entende que este é um contexto paradoxal ao exigir o profissionalismo dos professores no momento em que atravessam uma crise profunda e atenta para uma situação duplamente coercitiva, ou seja, ao exigir a profissionalização do ensino e, por outro lado, vivenciar a desvalorização profissional.

Deacordo com Nóvoa(2011), a educação vive "espartilhada" em uma dupla visão controversa, como a desconfiança e a aposta, desprestígio e responsabilização profissional e a desqualificação e a exigência de qualidade, como se a educação fosse habitada por profisionais de pouco valor e, por outro lado, nessa se depositassem todas as perspectivas de futuro.

Nesse sentido, Nóvoa (2007) propõe uma escola menos "transbordante", centrada na aprendizagem, como espaço público da educação, considerando como desafio o reconhecimento e credibilidade do trabalho docente, na busca de uma formação centrada nas práticas docentes.

Para Tardif (2000), os cursos de formação de magistério são idealizados e distanciados da pesquisa, quando deveriam ser embasados em pesquisas e reflexões críticas sobre as próprias práticas de ensino, a fim de lutar contra o abismo enorme que há entre teoria e prática. Quando o professor não compreende o seu contexto de trabalho, nem percebe o cotidiano escolar e as relações sociais em que está inserido, muito provavelmente, não conseguirá fazer a reflexão de suas práticas pedagógicas, como relata Vilela (2018, p. 215): “A dissociação entre a teoria e prática na formação docente coopera para formar um profissional incapaz de atuar como agente transformador e contribuir para a qualidade na educação", ou seja, a teoria deve assumir um poder formativo, permitindo a interpretação contextualizada da realidade ao se apresentar como possibilidade de superação de práticas fundamentadas em si mesmas.

Freire (1996) assegura que a prática educativa, enquanto formadora, deve se sustentar em uma prática docente científica, ética e transformadora. Isto é, deve ser mais do que treinar o educando para o desempenho de destrezas, é preciso ter a consciência de que ensinar é um ato político e não há neutralidade na educação. Essa deve ser uma forma de intervir no mundo e a possibilidade de mudar a realidade. Nas palavras do autor: "Ensinar não é transferir conhecimento, mas criar as possibilidades para a sua própria produção ou a sua construção" (FREIRE, 1996, p.25).

Segundo o autor, o educador deve ter compromisso com a transformação da educação e não deve ser um esperançoso ingênuo ou um espectador passivo diante do determinismo social, mas sim, assumir o papel de educador, atuando com competência profissional para que sua presença não passe desapercebida pelos alunos.

É sabido que a função do professor é ensinar e que é preciso ter conhecimentos específicos para o exercício da sua profissão, considerados como saberes docentes. Para Tardif (2014), os saberes docentes englobam os conhecimentos, as competências, as habilidades e as atitudes para ensinar. Esses são plurais e heterogêneos, provenientes de diferentes fontes e modificados ao longo da experiência pessoal e profissional.

Tardif (2014) considera que esses saberes profissionais são transmitidos pelas instituições de formação e devem ser articulados com os saberes desenvolvidos pelos professores em suas práticas cotidianas, sendo incluídos os conhecimentos das Ciências da Educação e da Pedagogia, assim como os saberes pedagógicos, embasados na didática e metodologia para o exercício da prática docente. Os saberes experienciais são baseados no cotidiano do trabalho e se constituem em fundamento da prática docente e da competência profissional que, ao serem incorporados à experiência orientam o saberensinar dos professores. Dessa forma, a partir de suas experiências pessoais e profissionais, o professor constrói a sua carreira e identidade profissional.

Pimenta (1999) acredita que os professores podem construir sua identidade profissional quando compreendem o ensino como prática social, mobilizando os saberes docentes que considera como saberes da experiência, do conhecimento e os pedagógicos. Para a autora, os saberes do conhecimento estão relacionados aos conhecimentos das especialidades de cada área no contexto da contemporaneidade, os saberes pedagógicos estão relacionados aos conhecimentos da didática e metodologia e os saberes da experiência são produzidos no cotidiano docente, na reflexão das práticas e na interação com os outros educadores.

\subsection{O curso de Pedagogia e os documentos legais brasileiros}

A Pedagogia como ciência se ocupa do estudo sistemático da educação, compreendendo o ato educativo como atividade humana intencional e como prática social. Como a educação ocorre, em muitos lugares e em diferentes modalidades, seu campo de atuação é amplo e não se refere apenas às práticas escolares.

O pedagogo deve ser visto como o profissional que pode atuar como docente ou como especialista em práticas educativas, orientando o processo de ensino e aprendizagem. A elevação da formação docente ao nível superior no país passa a ser prevista pelo artigo 62, da Lei de Diretrizes e Bases da 
Educação Nacional (LDB nº 9394/96):

A formação de docentes para atuar na educação básica far-se-á em nível superior, em curso de licenciatura de graduação plena, em universidades e institutos superiores de educação, admitida, como formação mínima para o exercício do magistério na educação infantil e nas quatro primeiras séries do ensino fundamental, a oferecida em nível médio, na modalidade Normal.

Posteriormente, foi alterada pela Lei $\mathrm{n}^{\circ} 13.415$, de 16 de fevereiro de 2017:

A formação de docentes para atuar na educação básica far-se-á em nível superior, em curso de licenciatura plena, admitida, como formação mínima para o exercício do magistério na educação infantil e nos cinco primeiros anos do ensino fundamental, a oferecida em nível médio, na modalidade normal.

No Brasil, ao longo de sua história, o curso de Pedagogia sempre teve como seu objeto de estudo os processos educativos em escolas e, em outros ambientes, a educação de crianças nos anos iniciais de escolarização, assim como a gestão educacional. Para Libâneo (2001), em uma visão do senso comum, educação e ensino sempre foram relacionados com ensinar crianças e a Pedagogia sempre foi um curso de formação de professores, segundo a tradição histórica brasileira.

Após um longo processo de consultas, de discussões e de análises da realidade educacional brasileira, foi aprovada, em 13 de dezembro de 2005, e instituída pelo Parecer CNE/CP n ${ }^{\circ}$ 1, de 15 de maio de 2006, as Diretrizes Curriculares Nacionais para o Curso de Pedagogia, precedido pelo Parecer CNE/CP $\mathrm{N}^{\circ} 5 / 2005$, que faz um breve histórico do Curso de Pedagogia e apresenta princípios, objetivos e organização do curso que serão apresentadas nos parágrafos seguintes.

O Decreto-Lei $n^{\circ}$ 1.190/1939 regulamentou o curso, oferecendo três anos de bacharelado em conteúdos específicos da área e mais um ano de licenciatura em Didática e a Prática de Ensino, conhecido como "esquema 3+1". Com a Lei da Reforma Universitária $\mathrm{n}^{\circ} 5.540$, de 1968 , foi permitida a oferta das habilitações em Supervisão, Orientação, Administração e Inspeção Educacional, eliminando a dicotomia entre bacharelado e licenciatura, mantida pela Lei $\mathrm{n}^{\circ} 4.024 / 1961$ e regulamentada pelo Parecer CFE n ${ }^{\circ}$ 251/1962.

O Parecer CFE n 252 e a Resolução CFE n 2, de 1969 possibilitavam a obtenção do título de especialista em educação e indicavam como finalidade do curso a preparação de profissionais da educação.

No início da década de 1980, várias universidades efetuaram reformas curriculares no curso de Pedagogia ao oferecer formação de professores para atuarem na Educação Infantil e nas séries iniciais do Ensino Fundamental, atentas às exigências do momento. Nesse período, cresceu a crítica sobre a dicotomia entre teoria e prática, problematizando o equilíbrio entre formação e exercício profissional, na medida em que aumentava o número de estudantes sem experiência docente em função do fato de o curso de Pedagogia tornar preferencial para a formação de docentes da Educação Infantil e das Séries
Iniciais do Ensino Fundamental.

Por outro lado, firmou-se a compreensão de que o campo de estudo da Pedagogia é o ensino e o trabalho pedagógico que se realiza na práxis social, tendo como referência o respeito às diferentes concepções teóricas e metodológicas, constituindose como o principal lócus da formação docente nos anos de 1990. Ao fazer a conexão entre formação inicial, exercício da profissão e formação continuada se têm na docência a base para o processo formativo e, como princípio, o respeito às diferentes concepções teóricas das áreas integradoras e subsidiárias à formação de educadores, respeitando a diversidade nacional e a autonomia pedagógica das instituições.

Portanto, a centralidade da formação do licenciado em Pedagogia está na pesquisa, no estudo do trabalho pedagógico e na ação docente, embasada em pesquisas de diferentes realidades, em consenso às ideias de Libâneo (2001), ao afirmar que a formação profissional do Pedagogo deve ser vista sob uma tríplice perspectiva: formação docente, como especialista e como pesquisador. De acordo com as DCN (Diretrizes Curriculares Nacionais) do curso de Pedagogia, essas devem reconhecer a função formativa da escola comprometida com uma sociedade justa e igualitária, construindo projetos educativos comprometidos com o fortalecimento das identidades dos estudantes e dos profissionais docentes da educação brasileira, a favor da educação emancipatória e transformadora.

O documento da Base Nacional Comum para a Formação Inicial de Professores da Educação Básica (BNC-Formação), por meio da Resolução $n^{\circ} 2$, de 20 de dezembro de 2019, tendo por referência o documento da Base Nacional Comum Curricular (BNCC-Educação Básica) para o desenvolvimento das competências gerais que garantem as aprendizagens essenciais nos aspectos intelectual, físico, cultural, social e emocional, necessários à formação integral do docente.

Neste documento fica estabelecido que a formação dos professores e demais profissionais da Educação tem como fundamento uma sólida formação básica, associando teorias e práticas pedagógicas, que envolvem uma formação docente inicial, continuada, articulada e de qualidade, assim como propõe a valorização da profissão docente e sua compreensão como agente formador.

Perante essas orientações e a crescente exigência social pela qualificação dos profissionais da educação, considera-se a formação inicial docente como um dos fatores essenciais para a elevação da qualidade da educação. Embora, elevar a formação docente em nível superior não tenha garantido uma formação profissional docente de qualidade. É necessário, pois que políticas públicas efetivas invistam na formação inicial docente, na valorização do magistério e na melhoria das estruturas escolares para a concretização de uma educação de qualidade.

\subsection{O programa PIBID}

O Programa Institucional de Bolsa de Iniciação à Docência - PIBID do Ministério da Educação - MEC foi instituído pelo 
Decreto $\mathrm{n}^{\circ} 6.096$, de 24 de abril de 2007 que visa proporcionar uma vivência do cotidiano das escolas públicas de Educação Básica e permite a troca de experiências e a cooperação entre Universidade e escola de Educação Básica ao ofertar bolsas da Coordenação de Aperfeiçoamento de Pessoal de Nível Superior - CAPES para os discentes na primeira metade dos cursos de licenciaturas (BRASIL, 2008).

Este programa oferece potencial para formar o professor como intelectual crítico ao aliar a formação teórica à prática e possibilitar a inter-relação entre os diferentes saberes docentes, com objetivos centralizados na formação dos licenciandos ao promover:

- O incentivo à formação de docentes em nível superior para a educação básica;

- A valorização do magistério;

- A elevação da qualidade da formação inicial de professores nos cursos de licenciatura, favorecendo a integração entre educação superior e educação básica;

- A inserção dos licenciandos no cotidiano de escolas da rede pública de educação, oportunizando experiências metodológicas, tecnológicas e práticas docentes de caráter inovador e interdisciplinar;

- A mobilização dos professores da educação básica como coformadores dos futuros docentes;

- A articulação entre teoria e prática necessárias à formação dos docentes, elevando a qualidade das ações acadêmicas nos cursos de licenciatura.(BRASIL, 2008).

A teoria assume um poder formativo ao permitir a interpretação contextualizada da realidade, articulando conhecimento teórico e prático, possibilita a elevação da qualidade dos cursos de licenciatura. Além disso, o PIBID permite que o licenciando possa construir a sua identidade profissional, a partir das reflexões acerca da profissão docente, ao longo do curso e da participação no programa. Por outro lado, mediante práticas colaborativas, os professores da Educação Básica das escolas públicas são mobilizados a serem coformadores dos futuros docentes, cooperando também para a melhoria do processo ensino e aprendizagem; ao desenvolverem ações conjuntas que trazem contribuições positivas para a construção dos saberes docentes.

\subsection{Projeto institucional PIBID Unopar}

A Universidade Pitágoras Unopar teve a oportunidade de participar, pela primeira vez, do Programa Institucional de Bolsa de Iniciação à Docência - PIBID, no ano de 2018, com o projeto institucional "Letramentos e Diversidades no Contexto Escolar", tendo por objetivo possibilitar uma imersão dos futuros professores em seu campo profissional, alinhada ao projeto educacional do país e aos objetivos do programa ofertado pela CAPES (Coordenação de Aperfeiçoamento de Pessoal de Nível Superior).

As atividades do PIBID Unopar tiveram início no dia cinco de setembro do ano de 2018, alinhadas ao programa nacional, visando contribuir para a valorização do magistério e elevar a qualidade da formação inicial de professores nos cursos de licenciatura, ao promover a integração entre Educação Superior e Educação Básica, por meio da articulação da formação inicial e continuada das licenciaturas. Foram compostos três núcleos de iniciação à docência para setenta e dois discentes bolsistas dos cursos de licenciaturas em Pedagogia e Educação Física e dezoito discentes voluntários, com início em setembro de 2018 e término em 31 de janeiro de 2020. Dessa forma, o licenciando obteve subsídios teórico-metodológicos para entender o fenômeno educacional, por meio do processo de reflexão, de ação e de compreensões sobre os desafios e complexidades do trabalho docente, no contexto escolar, contribuindo para a melhoria na formação profissional.

\subsection{As contribuições das pesquisas sobre PIBID}

Ao buscar pesquisas já concluídas sobre a contribuição do PIBID para a formação docente, no banco de dados da Biblioteca Digital Brasileira de Teses e Dissertações (BDTD), no período de 2014 a 2019, foram produzidas algumas teses e dissertações a este respeito, demonstrando a contribuição do programa na construção dos saberes docentes ao enfatizar práticas que favoreçam a aproximação entre universidade e escola.

Entre esses, foram selecionados dois estudos que tinham a temática sobre o PIBID e a Pedagogia, sendo esses: Neves (2014), que realizou a pesquisa em duas escolas municipais, analisando o processo de aprendizagem da docência das licenciandas do PIBID de Pedagogia a partir da análise das implicações, potencialidades e limitações dessas ações em seus processos de aprendizagem da docência e, o estudo de Eufrazio (2014), que buscou compreender como ocorre o processo de profissionalização das licenciandas do PIBID, analisando a aprendizagem da docência e dos saberes que a constituem. A autora aponta as potencialidades e os limites do programa na construção dos saberes docentes e evidencia as aprendizagens construídas no PIBID.

As duas pesquisas indicam que a imersão na escola e o convívio com professores e alunos das escolas parceiras, ao planejar ações e realizar atividades, possibilitaram ao licenciando, participante do PIBID, construir saberes docentes oriundos de práticas colaborativas e experiências coletivas.

Em outro estudo, Souza e Testi (2016) apresentam o potencial formativo do PIBID, quando inseridos no contexto escolar, os licenciandos são convocados a pesquisarem estratégias de ensino adequadas à realidade das escolas parceiras, fortalecendo a tríade ensino-pesquisa-extensão nos cursos de licenciatura em prol da qualidade na formação docente. As pesquisas apresentadas evidenciam as contribuições do PIBID para a formação inicial docente e quando a integração entre Universidade e escola da Educação Básica oportunizam experiências e práticas docentes em prol de uma melhor qualificação profissional.

\subsection{Coleta de dados}

A coleta de dados foi feita na Unopar - Unidade Piza - Londrina, com trinta licenciandos do PIBID Pedagogia, participantes dos três núcleos desenvolvidos na Instituição 
de Ensino Superior, sob o Projeto Institucional do PIBID CAPES "Letramentos e Diversidades no Contexto Escolar". Os participantes do PIBID de Pedagogia responderam às questões semiestruturadas sobre a participação no programa. $\mathrm{O}$ questionário possuía onze perguntas para que os licenciandos respondessem questões relacionadas com a compreensão dos conteúdos teóricos do curso, no que tange à prática vivenciada no PIBID e dos conhecimentos específicos (pedagógicos) para a atuação prática do pedagogo.

Quase todos os participantes eram do sexo feminino, sem obrigação de se identificar, preencheram alguns dados que permitiram conhecer o perfil dos participantes do programa. Destes participantes, a maioria tinha até vinte e cinco anos, cursando entre o quarto e o sexto semestre do curso. Todos os participantes estavam participando do PIBID entre um ano e um ano e seis meses, muitos deles participam desde o início das atividades em 2018, neste primeiro grupo formado na Instituição.

Verificou-se que todos foram inscritos no PIBID quando estavam cursando até $60 \%$ do curso de licenciatura, conforme previsto pelas orientações do programa, contribuindo, desta forma, para a formação inicial docente por meio da experiência vivenciada em contextos escolares. Entre os licenciandos, dezesseis informaram estar trabalhando em instituições educacionais ou realizando estágio remunerado ou não, desempenhando funções de auxiliar de sala, assistente educacional, secretária, professora de berçário e educação infantil, colaborando dentro e fora de sala de aula.

Considerando que a participação no programa possibilita a inserção do futuro professor em ambiente escolar e a vivência de práticas pedagógicas, o grupo de quatorze licenciandos, sem experiência profissional fora do estágio obrigatório e do programa, tiveram a possibilidade de fazer a inter-relação dos saberes necessários para o exercício da docência. De acordo com metodologia da análise de conteúdo, foi iniciada a análise das respostas dos pibidianos, permitindo as primeiras impressões para a construção das categorias de análise e posterior compreensão dos significados e inferência de conhecimentos na direção da confirmação ou negação das hipóteses levantadas durante a revisão bibliográfica.

As categorias de análise foram elaboradas a partir da classificação dos saberes docentes, com base em Pimenta (1999): "Saberes do conhecimento, Saberes pedagógicos e Saberes da experiência". A exploração dos dados coletados, fundamentada no referencial teórico da pesquisa, permitiram que as subcategorias fossem formadas para a construção das unidades de análise, baseadas nas respostas dadas pelos pibidianos.

\section{Resultados e Discussão}

Os resultados apresentados são análises parciais da pesquisa sobre as contribuições do PIBID para a formação inicial e a construção dos saberes docentes, conforme a análise da categoria "Saberes do conhecimento" (PIMENTA, 1999), que podem ser considerados como os saberes relacionados aos conhecimentos científicos aplicados à prática da docência. Para a autora, conhecer passa por um processo de trabalhar com as informações, processo este bem diferente de apenas informar. A educação, enquanto processo de humanização civilizatório, é prática social, sob a responsabilidade da escola e dos professores serem mediadores entre o aluno e a sociedade da informação.

Essa categoria pretende mostrar a relação entre o conhecimento científico do curso de graduação e o conhecimento prático vivenciado no PIBID, na percepção dos participantes do programa. Ao questionar os pibidianos sobre o que um pedagogo precisa saber para atuar na escola, buscamos verificar qual a compreensão sobre ser pedagogo. Ser pedagogo, configurouse em uma das subcategorias, organizando as respostas nas seguintes unidades de análise: 1. Competência profissional e pessoal, 2. Competência profissional e 3. Competência pessoal. Dos trinta participantes, dois licenciandos não responderam a esta questão.

O primeiro grupo é composto por dezesseis respostas, apontando que os conhecimentos necessários para exercer a função de pedagogo e estão ligados à competência profissional somados com a competência pessoal: "Um pedagogo precisa saber sobre a teoria, porém precisa ser muito mais do que a profissão exige, ele tem que ser humano e saber lidar com todas as situações" (P15). Nessas respostas transparecem a compreensão de que os conhecimentos necessários para ser pedagogo vão além do conhecimento adquirido na formação profissional: "Ter conhecimentos gerais, ética, responsabilidade, ter amplo saberes" (P21).

Há também a compreensão de que o pedagogo precisa conhecer a realidade escolar para atuar: "O pedagogo deve saber como lidar com a comunidade escolar, como solucionar os problemas enfrentados, conhecer a realidade de cada aluno e ter um olhar individual, saber dialogar, ter respeito e buscar soluções de melhoria" (P30). Entre as respostas, uma dessas revela a função do pedagogo como especialista em práticas educativas, atuando como coordenador pedagógico: "Saber ser paciente e atencioso em primeiro lugar, como lidar diretamente com alunos, pais, funcionários, saber conversar, saber as normas e regras do colégio e o PPP" (P17).

Assim como, outra resposta evidencia a função do pedagogo como docente:

Um pedagogo tem que estar preparado para a realidade que enfrentará na sala de aula, e por isso ele precisa saber como deve 'se portar' sendo ético, construtivo, justo e ter uma visão ampla para poder alfabetizar as crianças e estar sempre 'aprendendo' para um melhor ensino-aprendizagem. Ter conhecimento teórico como base para atuação, primeiramente (P28).

Portanto, fica evidente o papel do pedagogo como "o profissional que atua em várias instâncias da prática educativa, direta ou indiretamente, ligadas à organização e aos processos de transmissão e assimilação de saberes e modos de ação" (LIBÂNEO, 2001, p. 11). Esta concepção se mostra alinhada 
às DCN de Pedagogia, instituída em 2006, no seu artigo $3^{\circ}$, parágrafo único, incisos I, II e III, que determina que para a formação do licenciado é essencial:

I - o conhecimento da escola como organização complexa que tem a função de promover a educação para e na cidadania;

II - a pesquisa, a análise e a aplicação dos resultados de investigações de interesse da área educacional;

III - a participação na gestão de processos educativos e na organização e funcionamento de sistemas e instituições de ensino (BRASIL, 2006).

Nesse sentido, a imersão no ambiente escolar, proporcionada por meio do PIBID, permitiu a compreensão de que o exercício da docência exige competência profissional e pessoal, na medida em que a docência exige muito mais do que saber apenas ensinar o conteúdo, conforme as respostas dadas pelos licenciandos.

No segundo grupo de respostas, onze pibidianos afirmaram que os conhecimentos necessários para exercer a função de pedagogo estão ligados à competência profissional. Assim como ocorreu no primeiro grupo de respostas, alguns ressaltaram a função docente ou de coordenador, mas sem relacionar competência profissional e pessoal:

O papel de um pedagogo é muito importante e de extrema responsabilidade. $\mathrm{O}$ pedagogo precisa ter uma boa gestão, pois normalmente é ele que organiza as formações dos professores, revisa os planos de aula, é o que conversa diretamente com os pais (P8).

Acho que um pedagogo deve estar a par de tudo que está relacionado a área docente, tanto em assuntos dos professores quanto dos alunos (P24).

Embora as respostas do pibidianos evidenciem a compreensão de que existem conhecimentos necessários para um pedagogo ser um profissional competente, os mesmos necessitam relacionar os conhecimentos aprendidos no curso de formação com a prática docente. Sendo assim, o PIBID se apresenta com possibilidades promissoras para aliar conhecimento teórico e prático, contribuindo para a formação inicial docente.

Nessa perspectiva, duas respostas revelaram que o PIBID oportuniza relacionar conhecimentos teóricos e práticos, contribuindo para uma melhor formação profissional:

Penso que tudo o que é ensinado no tempo da graduação, todas as disciplinas... (P6)

Antes de mais nada o pedagogo precisa conhecer a sala de aula, e ter a interação com o aluno e a aprendizagem, e ainda ter uma base teórica para saber lidar com os desafios a serem enfrentados. (P9)

Dessa maneira, concorda-se com Pimenta (2019), ao afirmar que o professor desenvolve compreensões sobre o seu trabalho e a própria escola durante o processo de profissionalização, ao combinar conhecimentos teóricos, experiências pessoais e convivência com colegas, alunos e autoridades escolares.

Apenas uma resposta faz parte do terceiro grupo que acredita na competência pessoal do pedagogo, sem relacionar aos conhecimentos adquiridos na formação: "Bom. A postura que os professores têm faz com que tenha um certo controle da sala, ele pode brincar às vezes como também dar bronca se necessário para ter um certo controle na bagunça" (P1).

Embora não explicite a relação entre competência profissional e pessoal, acredita-se que ao falar sobre "postura" do professor, o pibidiano fez referência aos conhecimentos adquiridos no curso de formação profissional.

É possível verificar que algumas das respostas estão alinhadas ao que a legislação propõe, quando nas DCN de Pedagogia, no artigo $5^{\circ}$, apontam dezesseis aptidões necessárias para o pedagogo desempenhar sua função. Entre essas são elencadas aptidões relacionadas à competência profissional e pessoal comprometida com a educação emancipatória: "I - atuar com ética e compromisso com vistas à construção de uma sociedade justa, equânime, igualitária" (BRASIL, 2006), atuando como docente: "VI - aplicar modos de ensinar diferentes linguagens, Língua Portuguesa, Matemática, Ciências, História, Geografia, Artes, Educação Física, de forma interdisciplinar e adequada às diferentes fases do desenvolvimento humano" (BRASIL, 2006), ou na função de coordenador: "VIII - promover e facilitar relações de cooperação entre a instituição educativa, a família e a comunidade" (BRASIL, 2006).

Ressalta-se que segundo este mesmo documento, o pedagogo deve estar apto a: "XII - participar da gestão das instituições contribuindo para elaboração, implementação, coordenação, acompanhamento e avaliação do projeto pedagógico" (BRASIL, 2006), integrando o papel do Pedagogo como docente, especialista e pesquisador das atividades educativas.

Para Pimenta et al. (2017, p. 15), ao discutir a formação de professores proposta pela DCN de Pedagogia (BRASIL, 2006), chama a atenção para o amplo campo de atuação profissional do pedagogo, ao propor uma formação que excede o campo da docência, para atuar em áreas de gestão educacional e em espaços não escolares, tendo por consequência uma: "formação frágil, superficial, generalizante, fragmentada, dispersiva e sem foco".

De acordo com Gatti et al. (2019), as dezesseis aptidões necessárias aos egressos de Pedagogia diversificam e fragmentam a formação na licenciatura de Pedagogia, na medida em que a opção por uma formação ampla e genérica não consegue responder aos desafios das diferentes realidades, nas quais as práticas educacionais vêm sendo realizadas, bem como não atende a demanda de algumas dessas aptidões por uma formação mais específica.

Mazzotti (2011) considera que a Pedagogia pode ser constituída como uma ciência da prática educativa e seu objeto de conhecimento seria o fazer educativo e sua efetividade em ciscunstâncias e múltiplas efetividades. Por este motivo, o pedagogo pode ser considerado como o profissional que procura relacionar o fazer prático com o fazer teórico na educação, exercendo um papel crítico-reflexivo no ambiente escolar, em busca de uma educação de qualidade na construção de uma sociedade democrática. 


\section{Conclusão}

Tendo em vista os aspectos observados dos trabalhos já publicados, o PIBID tem potencial para contribuir para formação inicial docente e permitir o desenvolvimento de saberes relacionados à docência. Identificar as principais contribuições para a formação do discente daIES após passar pelo programa se tornou imprescindível, uma vez que os resultados podem impactar nas ações futuras dos projetos institucionais para o curso de Licenciatura em Pedagogia.

A análise parcial da primeira categoria Saberes do Conhecimento e a subcategoria Ser Pedadagogo possibilita inferir que a maioria dos licenciandos conseguiu relacionar as competências profissionais e pessoais no exercício da docência.

As experiências vivenciadas pelos licenciandos, no PIBID, possibilitaram contribuir para a construção dos saberes docentes, quando o licenciando compreendeu o papel do Pedagogo no processo de ensino e aprendizagem, em busca de ações educativas efetivas para a conquista de uma educação de qualidade. Embora exista um grupo de licenciandos que ainda não evidenciaram nesta categoria, perceber a importância das competências profissionais somadas às competências pessoais para ser docente, outras questões estão sendo analisadas que poderão implicar em novas compreensões do PIBID da instituição.

Nesse sentido, destaca-se a necessidade de ações que permitam reflexões sobre a formação inicial ao buscar nas Ciências da Educação explicações ou soluções para as diferentes situações do cotidiano da docência, estreitando o distanciamento entre Educação Superior e Básica.

Considera-se que o PIBID Pedagogia, na Universidade PitágorasUnopar - Londrina, tem alcançado seus objetivos centralizados na elevação da qualidade da formação inicial docente e na valorização do magistério ao aliar a formação teórica e a prática que permitam ao licenciando conectar sua formação inicial ao exercício da profissão para a construção dos saberes docentes e da própria identidade profissional.

\section{Referências}

BRASIL. Ministério da Educação. LDB - Lei no 9394/96, de 20 de dezembro de 1996. Estabelece as Diretrizes e Bases da Educação Nacional. Brasília: MEC, 1996.

BRASIL. Ministério da Educação. Lei $n^{\circ} 13.415$, de 16 de fevereiro de 2017. Disponível em: http://www.planalto.gov.br/ ccivil_03/_Ato2015-018/2017/Lei/L13415.htm\#art7 Acesso em: 10 set. $20 \overline{2} 0$.

BRASIL. Ministério da Educação. Parecer Conselho Nacional de Educação Conselho Pleno $n^{\circ}$ 5/2005, de 13 de dezembro de 2005. Aprova as Diretrizes Curriculares Nacionais para o Curso de Pedagogia. Disponível em: http://portal.mec.gov.br/cne/ arquivos/pdf/pcp05_05.pdf Acesso em: 10 set. 2020.
BRASIL. Ministério da Educação. Parecer Conselho Nacional de Educação Conselho Pleno $n^{\circ}$ 1/2006, de 15 de maio de 2006. Institui as Diretrizes Curriculares Nacionais para o Curso de Pedagogia. Disponível em: http://portal.mec.gov.br/cne/arquivos/ pdf/rcp01_06.pdf Acesso em: 10 set. 2020.

BRASIL. Ministério da Educação. Programa Institucional de Bolsas de Iniciação à Docência - PIBID. Disponível em: http:// www.Capes.gov.br/educacaobasica/CapesPIBID. 2019. Acesso em: 21 abr. 2020.

EUFRÁZIO, V. L. O Programa Institucional de Bolsa de Iniciação à Docência (PIBID): dimensões do desenvolvimento profissional de licenciandas do curso de pedagogia. 2014 Disponível em: http://bdtd.ibict.br/vufind/Record/UFV_ f937253b780d9b64842358bfef6d457c

Acesso em: 14 jun. 2020.

FREIRE, P. Pedagogia da Autonomia: saberes necessários à prática educativa. São Paulo: Paz e Terra, 1996.

GATTI, B. A. et al. Professores do Brasil: novos cenários de formação. Brasília: UNESCO, 2019.

MAZZOTTI, T.B. Estatuto de cientificidade da Pedagogia. In: PIMENTA, S.G. Pedagogia: ciência da educação? São Paulo: Cortez, 2011. p.19-46.

NEVES, E.R. Aprendendo a docência: processos de formação de licenciandas em Pedagogia integrantes do Programa Institucional de Bolsa de Iniciação à Docência (PIBID). 2014. Disponível em: http://bdtd.ibict.br/vufind/Record/ UFV_1c70270c64e3d6c37ffe1aa0b0ec97d Acesso em: 18 abr. 2020 .

NÓVOA, A. As ciências da Educação e os processos de mudança. In: PIMENTA, S.G. Pedagogia: ciência da educação? São Paulo: Cortez, 2011, p. 85-126.

NÓVOA, A. Os desafios do trabalho do professor no mundo contemporâneo. São Paulo: SINPRO-SP, 2007.

PIMENTA, S.G. Formação de professores: identidade e saberes da docência. In: PIMENTA, Selma Garrido. (Org). Saberes pedagógicos e atividade docente. São Paulo: Cortez, 1999. p.1534.

PIMENTA, S. G. et al. Os cursos de licenciatura em pedagogia: fragilidades na formação inicial do professor polivalente. Educ. Pesq., v.43, n.1, p.15-30, 2017.

SOUZA, N.C.A.T.; TESTI, B.M. O PIBD no contexto das políticas de formação inicial: um novo olhar para o processo de iniciação à docência. Imagens Educ., v.6, n.1, p.50-58, 2016.

TARDIF, M. Saberes profissionais dos professores e conhecimentos universitários Elementos para uma epistemologia da prática profissional dos professores e suas consequências em relação à formação para o magistério. Rev. Bras. Educ., n.13, p.524, 2000.

TARDIF, M. Saberes docentes e formação profissional. Petrópolis: Vozes, 2014.

VILELA, M.V.F. O contexto atual do PIBID e suas contribuições para a formação docente no IFMT. In: MONTEIRO, S.B.; OLINI, P. (Org.). Coleção Encontro Nacional de Didática e Prática de Ensino: didática, saberes docentes e formação. Cuiabá: EduFMT. 2019, p. 214-226. 